\title{
Development of the system form for concrete casting in the girder bridge slab-purlin hanging system
}

\author{
Soojin Sung ${ }^{1}$, Jeeyoung Lim ${ }^{2}$, Shraddha Palikhe ${ }^{3}$, Kyungbo Han ${ }^{4}$, Sunkuk Kim ${ }^{5, *}$ \\ 1, 2, 3, 4, 5 Kyung Hee University, Seoul, South Korea
}

\section{Index Terms}

Girder Bridge

Slab Concrete Casting

System Form

Cost Analysis

Received: 19 October 2014

Accepted: 20 July 2015

Published: 22 February 2016

\begin{abstract}
Traditional form for concrete pouring in the slab of the girder bridge is timeconsuming and requires a lot of human resources. In addition, there are safety problems when installing and removing the forms and damage of materials, leading to an increase in cost. SMART from Purlin support system developed to solve these problems is to install support in the upper flange of the girder to support the forms of the slab. However, the complicated support structure of forms resulted in various problems, including increased production and transport costs and decreased use on-site owing to the lifting method. To supplement such problems, the SMART form Purlin hanging system was developed. This study aims to develop a form system for concrete pouring in the slab of the girder bridge. In addition, it is to check whether the formwork cost is reduced when the SMART form purlin hanging system is adopted through a cost analysis by comparing with the traditional form.
\end{abstract}

(C) 2016 TAF Publishing. All rights reserved.

\section{INTRODUCTION}

Bridge is classified into 8 types depending on the upper structure type - Slab bridge, Girder bridge, Truss bridge, Arch bridge, Rahmen bridge, Cable stayed bridge, Suspension bridge and Extradosed bridge. Among these bridges, Girder bridge is the most widely used bridge type since the load is directly transferred to the pier and abutment by the girder, which makes the structural analysis and design simple. Such girder type accounts for $75 \%$ of the total bridge constructions in Korea and takes $80 \%$ of the total construction cost [1]. In particular, a demand for railway bridges, such as high-speed railways and urban railroads has been increasing recently, resulting in a continuous increase of new girder bridges annually [2] and [3].

\footnotetext{
*Corresponding author: Sunkuk Kim

E-mail: kimskuk@khu.ac.kr
}

The girder, produced in factory or on site, is installed on top of the pier and a slab is installed on its top side. Here, unlike the girder which is precasted, concrete is poured into the slab on site, which makes the quality and productivity of slab concrete closely related to the forms. When the existing traditional forms are used, several problems, like material loss, increased cost, degraded concrete quality, extended duration and safety accidents may occur.

SMART form Purlin support system (hereinafter referred to as "SMART form ver.1") is a type of system form developed to solve the problems of conventional concrete pouring on bridge slabs [4]. However, SMART form ver.1 has a complicated structure as the upper part of the girder's lower flange supports the support of forms. This increased the cost for producing forms, and as the self-load increased, an additional lifting skill was needed. As a result, the application of system forms on site decreased. 
SMART form Purlin hanging system (hereinafter referred to as "SMART form ver.2") is developed to improve the weaknesses of SMART form ver.1, including the increased production and transport costs caused by the complicated support structure and decreased application on site.

\section{A. Development of SMART form ver.2}

Girder bridge work, in which a precast girder is installed on top of the pier and concrete is poured into the slab with a form in the upper girder, involves a slab work that requires a lot of time and manpower and generates several problems. Especially, the installation of forms and rebar placing that is highly dependent on the manpower working at a high altitude, and the removal of forms where a crane cannot be used are extremely difficult, which increases the labor cost and the risk of safety accidents. Owing to the small working space when removing forms, there is a great deal of loss in materials. As a result, the use of form materials decreases, increasing the total cost of concrete pouring on slabs.

To solve these problems of existing concrete pouring on slabs, Half PC and deck plate methods are developed. Yet, they are low in constructability, difficult to be maintained and low in economic feasibility, which makes them difficult to be applied on site [5], [6] and [7].

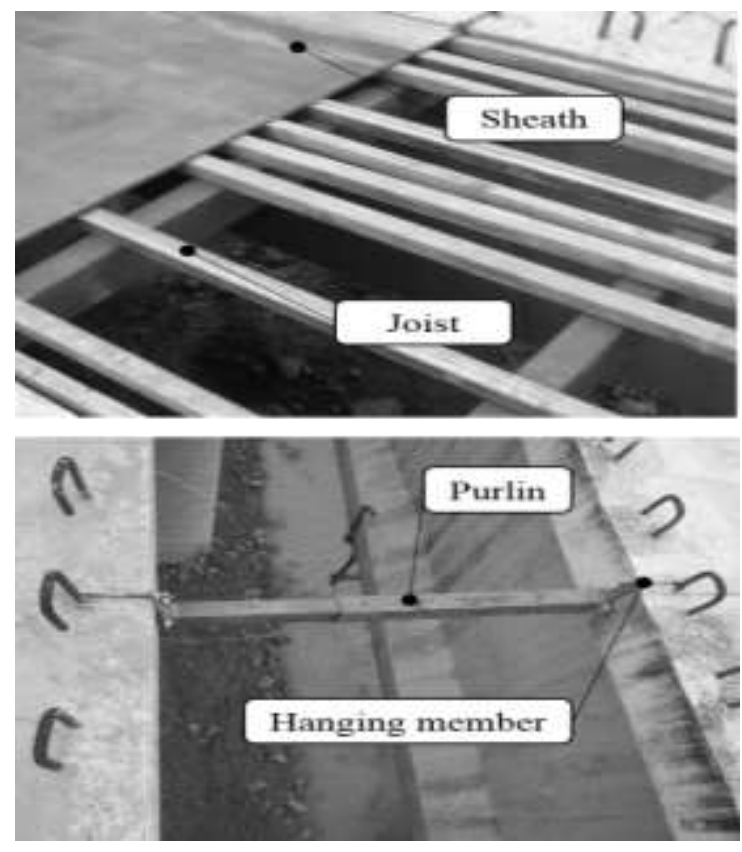

Fig. 1. Current state of traditional form
SMART form ver.2 is a temporary device hung on the upper girder flange as shown in Figure 2, and it is used for concrete casting of bridge slab. Unlike ver.1 where it is hung on the lower girder flange, SMART form ver.2 uses the upper girder flange.

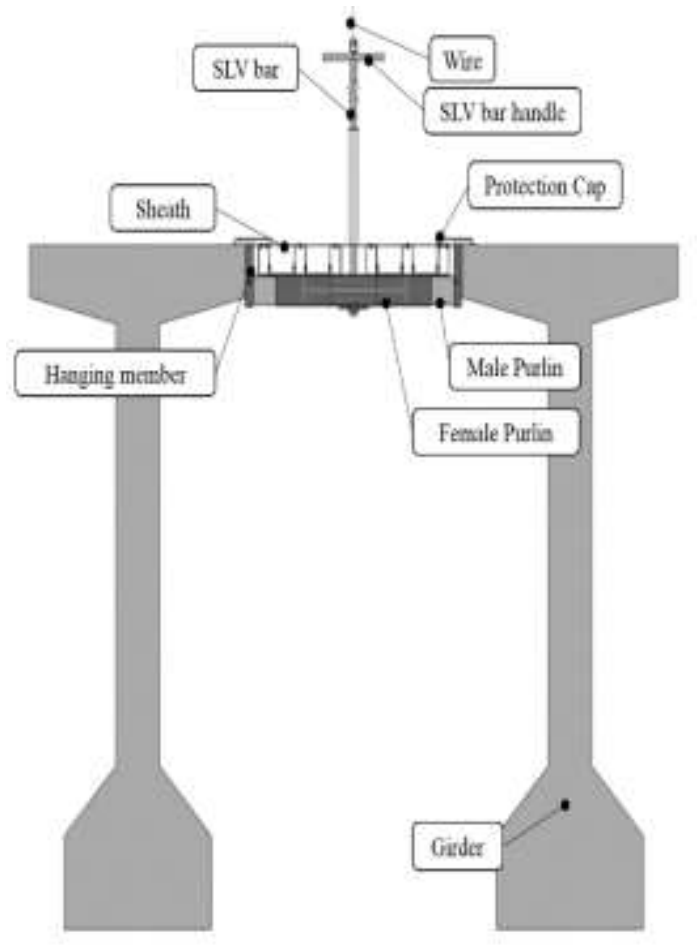

Fig. 2. Segmental names of SMART form ver. 2

As illustrated in Figure 3, SMART form controls the installation and removal of forms by moving the Gear located inside the Purlin and by rotating the SLV bar handle in the upper section of SLV bar. When the SLV bar handle is turned counterclockwise, the male purlin moves towards the girder based on the interaction of the pinion gear and rack gear installed on the SLV bar. On the contrary, when the SLV bar handle is turned clockwise, the male purlin moves inside the female purlin as shown in Figure 3-(b), making a space between the system form and the girder.

To easily remove the system form after the concrete pouring on slab, a space to move a hanging member is needed. Thus, in case of SMART form, a plastic protection cap is installed in the upper part of the hanging member before pouring the concrete on slab as shown in Figure 4(a) \& (b), to secure a space to move the hanging member as illustrated in Figure 4-(c) \& (d). Here, since the protection cap can move around during the process of concrete pouring, use nails for concrete to fix the protection cap on the girder. 


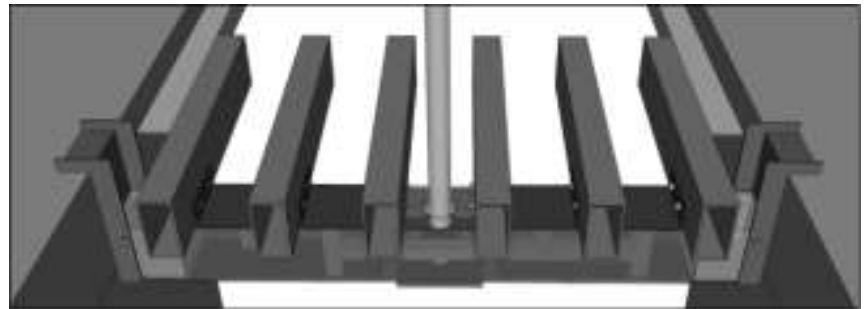

(a) System form installed

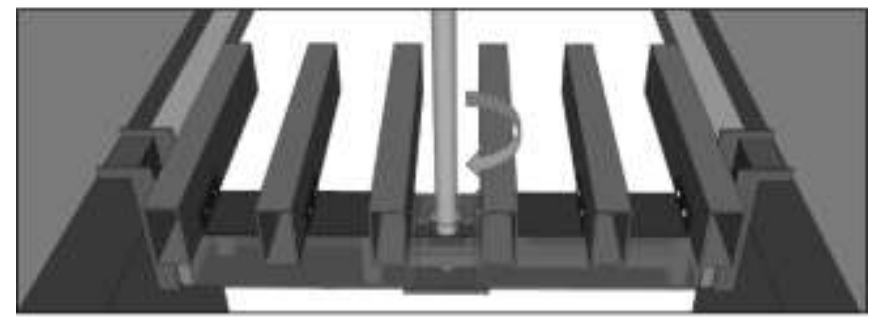

(b) System form uninstalled

Fig. 3. Behavior of SMART form ver. 2

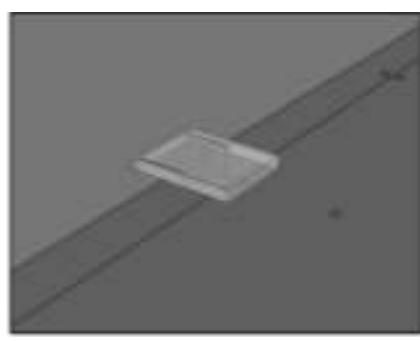

(a) Cap placed

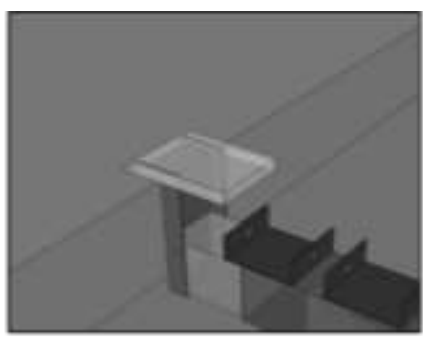

(b) Cap placed,

Sheath removed

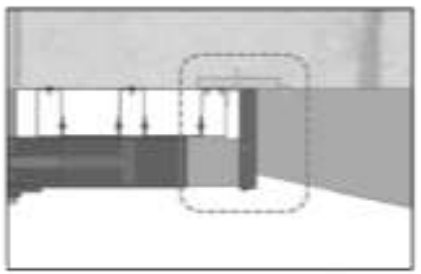

(c) Hanging member placed

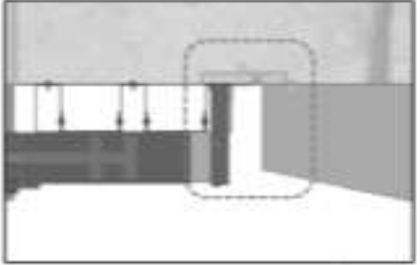

(d) Hanging member removed
Fig. 4. Protection cap

\section{B. Review on Site Applicability of SMART form ver.2}

The process of installing the designed SMART form is as described in Figure 5. Above all, the surface of girder flange should be cleared up so that the system form can be installed (a). Then, the system form is connected to a wire using the wire connector of SLV bar, and the form is moved to a location in the upper girder using the lifting device (b), (c). Turn the SLV bar counterclockwise to extend the purlin as much as possible (d). When the system form is deployed, remove the wire connected to the upper SLV bar and the SLV bar handle, and then install a sleeve onto the SLV bar. Install the protection cap using nails for concrete, and seal the gap between the sheath and the girder with a tape to prevent concrete leaking (e). When it is all done, install the side forms at both ends and perform concrete pouring (f).

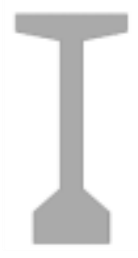

(a) Preparing

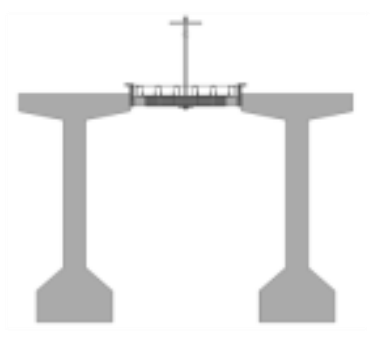

(c) Position setting

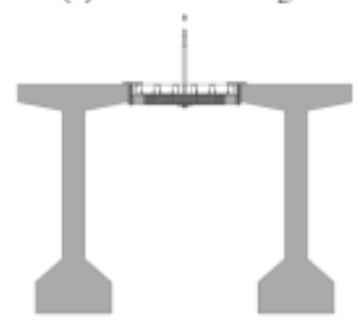

(e) Protection cap, sleeve setting \& SLV bar handle, wire removing

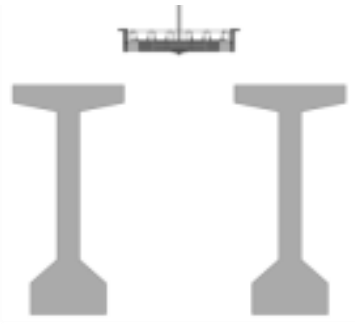

(b) Bring system form

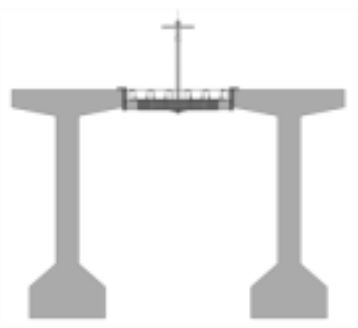

(d) SLV bar handle rotating

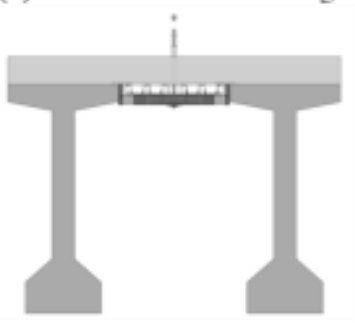

(f) Side form setting \& concreting
Fig. 5. Installing process of SMART form ver. 2

Owing to the concrete-poured slab in the upper part, the process of removing forms is different from the process of installing them. The process of removing the SMART form is as described in Figure 6. Cure the concrete-poured slab until it reaches the reference strength (a). Prior to removing the system form, a wire and SLV bar handle are installed to lift the form (b). Turn the SLV bar handle clockwise to separate the hanging member from the girder, and detach the SLV bar handle so that the wire can go down through the sleeve. Then, let the system form go straight down (c), (d). When the system form is removed, cut the sleeve remaining in the slab according to the concrete surface and grout the empty space (e), (f). 


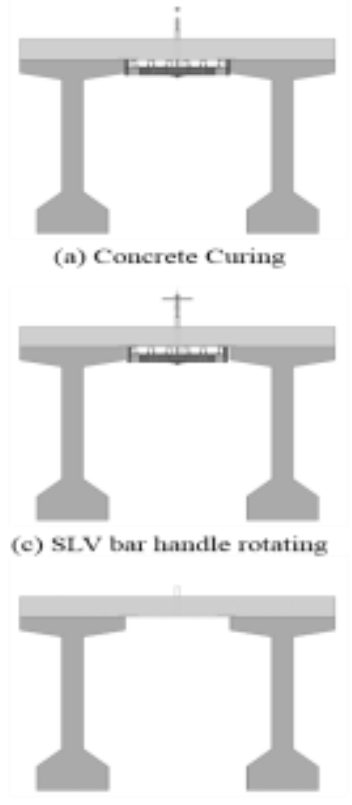

(e) Sleeve cutting

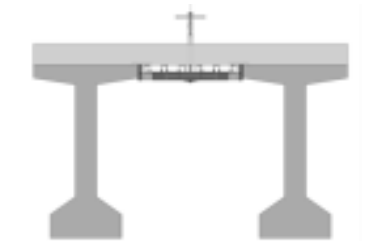

(b) SLV bar handle, wire setting

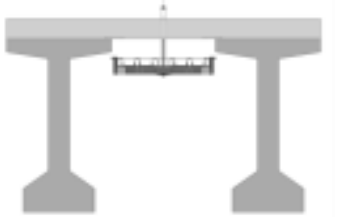

(d) SLV bar, System form removing

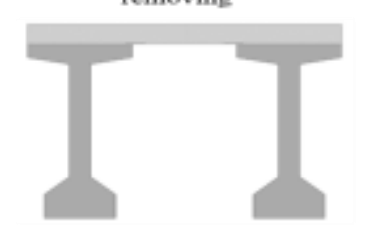

(1) Sleeve bole grouting
Fig. 6. Removing process of SMART form ver. 2

The cost for production, installation and removal was analyzed for both SMART form ver.2 and the existing method [8]. The traditional form requires additional temporary works like installing a post, yet SMART form does not need any. In addition, it uses purlins with a smaller section, so the quantity increases, and a wooden sheath is manually installed using a wooden joist. This requires a lot of manpower when compared to SMART form, assuming the work in the same section. When the conventional method is applied, it requires approximately $\$ 6,500$ to install 2 span $(50 \mathrm{~m})$, whereas only $\$ 1,700$ is needed for SMART form ver.2, according to the estimation of costs for producing, installing and removing forms. Therefore, around $26 \%$ of the cost applied with the conventional method can be spent to produce, install and remove the forms when SMART form ver.2 is adopted.

\section{CONCLUSION}

SMART form ver.2 is developed to solve the problems of conventional concrete pouring on bridge slab related to the construction duration, cost, quality and risk of safety accidents. The process of installing and removing SMART form ver.2, and its economic feasibility were examined. The results drawn from the study are as described below.
First, SMART form ver.2 supports the system load using the upper girder flange, which is a relatively simple structure that reduces the cost for producing forms. Furthermore, it uses a gear to control the overall system, making it easier to install and remove the forms with a little force. Also, it can respond to various girder sections without adjusting the length as it moves in a lateral direction.

Second, a systematic behavior of forms reduces the work duration, prevents any damage to the form members and reduces the ratio of manual work, ultimately cuts down the manpower input when compared to the conventional method. Thus, around $26 \%$ of the cost applied with the conventional method can be spent to produce, install and remove the forms when SMART form ver.2 is adopted.

The study identified the field effectiveness of SMART form ver.2 developed based on the cost-effectiveness. Further studies related to structural designs and analysis on geometric feasibility based on this study should be conducted.

\section{REFERENCES}

[1] "Bridge baseplate construction method using LBDECK, " Korea Association of Construction Engineering \& Management, vol. 12, no. 3, pp. 23-28.

[2] Ministry of Land, "The state of road bridge and tunnel in Korea," Infrastructure and Transport, 2015.

[3] Ministry of Land, "Korean agency for infrastructure technology advancement," Infrastructure and Transport, 2013.

[4] J. Lim, W. Hong, J. Kim and S. Kim, "Basic study of the system form for concreting the bridge slab," HKICE, pp. 79-86, 2014.

[5] S. Ahn, "Bridge top construction with M.S.S (Movable Scaffolding System)," Korean Society of Civil Engineers Magazine, vol. 44, no. 12, pp. 74-87, 1996.

[6] Y. Jeong, H. Koo, K. Lee and Y. Shin, "Economical erection method of cantilever bridge deck using permanent steel form bolted to girders," in Korean Society of Civil Engineers Conference \& Civil Expo (pp. 1688-1691), 2007.

[7] A. H. Moira, Deck Forms for Girder Bridges. Aberdeen Group, Illinois, 1994.

[8] Korea Institute of Civil Engineering and Building Technology, "Standard of construction estimate," 2015.

— This artcle does not have any appendix. 